\title{
ATENDIMENTO EDUCACIONAL ESPECIALIZADO ENVOLVENDO ALUNOS COM DEFICIÊNCIA VISUAL NA EDUCAÇÃO FÍSICA ESCOLAR
}

\author{
SPECIALIZED EDUCATIONAL CARE INVOLVING STUDENTS WITH \\ VISUAL IMPAIRMENT IN PHYSICAL SCHOOL EDUCATION
}

\section{ATENCIÓN EDUCATIVA ESPECIALIZADA A ALUMNOS CON DISCAPACIDAD VISUAL EN LA EDUCACIÓN FÍSICA ESCOLAR}

\author{
Lizete Wasem Walter*, Gabriela Simone Harnisch**, \\ Douglas Roberto Borella**
}

\section{Palavras chave: Aluno com deficiência visual. Aprendizado. Escola. Atendimento Educacional} Especializado.

Keywords: Student with visual impairment. Learning. School. Specialized Educational Service

Palabras clave: Estudiante con discapacidad visual. Aprendizaje. Escuela. Atención Educativa Especializada.
Resumo: O estudo teve como objetivo verificar o efeito da prática do Atendimento Educacional Especializado (AEE) visando à aprendizagem dos conteúdos da disciplina de Educação Física em alunos com deficiência visual. Caracteriza-se como pesquisa-ação. Participaram do estudo três alunos com deficiência visual, dois professores de Educação Física e dois pesquisadores. Os instrumentos foram protocolos de pré e pós-testes e entrevistas pessoais. Os dados foram analisados de forma qualitativa. Os resultados evidenciaram progressão do aprendizado da referida disciplina realizada no AEE. Constatou-se, ainda, que os alunos não participam de todas as aulas de Educação Física, e que a função do AEE ainda é desconhecida pelos professores investigados. Dessa forma, conclui-se que na prática ainda são excluídos os conhecimentos desta disciplina aos alunos com deficiência visual por meio do AEE mesmo quando se notam seus benefícios.

Abstract: The study looked into the effect of the practice of Specialized Educational Care (ESC) aiming at learning of Physical Education contents for visually impaired students. It is characterized as action research. Participants were three visually impaired students, two Physical Education teachers and two researchers. The instruments were pre- and post-test protocols and personal interviews. Data were analyzed qualitatively. The results showed progression of learning of that discipline in ESC. In addition, students do not participate in all Physical Education classes and ESC's role is still unknown to participant teachers. Therefore, in practice, knowledge of the subject is still excluded to visually impaired students through ESC even when its benefits are noted.

Resumen: El estudio tuvo como objetivo verificar el efecto de la práctica de la Atención Educativa Especializada (AEE) en el aprendizaje de los contenidos de la disciplina de Educación Física en estudiantes con discapacidad visual. El estudio se caracteriza como investigación acción. Participaron tres alumnos con discapacidad visual, dos maestros de Educación Física y dos investigadores. Los instrumentos fueron protocolos previos y posteriores a las pruebas y entrevistas personales. Los datos fueron analizados cualitativamente. Los resultados mostraron la progresión del aprendizaje de esta disciplina realizadas en la AEE. Se observó que los estudiantes no participan en todas las clases de Educación Física y que los maestros investigados aún desconocen la función de la AEE. Así, se concluye en la práctica que el conocimiento de esta materia aún excluye a los estudiantes con discapacidad visual a través de la AEE, incluso cuando se notan sus beneficios.
*Universidade Estadual de Campinas. Campinas, SP, Brasil. E-mail:

lizeteewasem@gmail.com

**Universidade Estadual do Oeste do Paraná. Marechal Cândido Rondon, PR, Brasil. E-mail: agaby_@hotmail.com; douglasedufisica@yahoo.com.br

Recebido em: 08-10-2019 Aprovado em: 05-11-2019 Publicado em: 25-03-2020 


\section{INTRODUÇÃO}

A disciplina de Educação Física (EF) foi incrementada formalmente dentro da proposta político-pedagógica das escolas brasileiras pela lei $n^{\circ} 9.394$ (BRASIL, 1996) e tornou-se obrigatória a partir de 2001 com uma alteração a referida lei (BRASIL, 2001b). De modo à mostrar sua importância, as Diretrizes Curriculares Estaduais (DCE'S), salientam que a EF atribui a possibilidade dos alunos terem acesso ao conhecimento de uma forma mais crítica à respeito das práticas corporais, relacionando-as aos aspectos históricos, políticos, econômicos e sociais da sociedade. Deste modo, indo além da aptidão física e performance esportiva, mas também levando em conta o desenvolvimento cognitivo, afetivo-social e motor dos alunos (PARANÁ, 2008).

De acordo com Rodrigues e Darido (2008) é importante que a EF evidencie as manifestações da cultura corporal de movimento de acordo com a realidade de cada qual, para que a prática faça sentido para todos. Neste sentido, integrada no currículo, a EF deve ter em consideração o direito exposto na Constituição Federal Brasileira de 1988, no artigo 208 , que o respeito às diferenças torna-se teorizado no ambiente escolar quando mostra que o aluno com deficiência tem o direito de estar participando das ações educacionais no ensino regular (BRASIL, 1988). Pensando nesse dever, autores como Conceição, Vassoler e Frasson, (2014); Lara e Pinto, (2017); Cunha e Gomes, (2017), propagam a ideia da Educação Inclusiva. Esta convém em transpor o aprendizado a todos, independentemente das dificuldades e limitações que cada um tem (UNESCO, 1994).

A ideia da inclusão aparece como um processo de democratização da escola, conscientizando de que a responsabilidade é educar todos (KAFROUNI; PAN, 2001; BRASIL, 2008; 2015). Pensando na inclusão as Diretrizes Nacionais para a Educação Especial na Educação Básica, salientam que "os sistemas de ensino devem matricular todos os estudantes, cabendo às escolas organizarem-se para o atendimento aos educandos com necessidades educacionais especiais, assegurando as condições necessárias para uma educação de qualidade para todos" (BRASIL, 2001a, p.1).

Tendo isso em vista, abarca-se o Atendimento Educacional Especializado (AEE), o qual é oferecido de forma obrigatória pelos sistemas de ensino e tem como objetivo complementar a formação do aluno com deficiência, ou seja, não substituir, mas suplementar o que lhe foi transmitido no ensino regular, de maneira que seja levado mais em consideração as limitações dele. É realizado, de preferência, nas escolas comuns, em um espaço físico, denominado Sala de Recursos Multifuncional (SRM), descrito no projeto político pedagógico de cada escola - PPP (BRASIL, 2001; 2008; ROPOLI et al., 2010).

Já que o AEE normalmente é ofertado por educadores especiais, os quais não necessariamente possuem formação em Educação Física (MUNSTER; ALVES, 2018), cabe ao professor das SRMs e os professores do ensino regular manterem um diálogo constante, objetivando o aprimoramento de todos os conteúdos trabalhados no ensino regular aos alunos com deficiência que frequentam a respectiva sala (BRASIL, 2008). 
Neste ínterim, a Educação Física não pode ficar apática no processo de inclusão escolar da pessoa com deficiência, visto que esta tem importante intervenção na cultura humana (SILVA; SANTOS; FUMES, 2014). Por isso, ações compartilhadas entre o professor de Educação Física e o de Educação Especial deve ser possível no contexto do ensino regular (SOARES; BAPTISTA, 2015).

Deste modo, tendo em vista que a SRM do Núcleo Regional de Educação, localizada no município de Marechal Cândido Rondon-PR é frequentada por três alunos que apresentam deficiência visual (DV), em que esta se classifica desde a visão subnormal até a cegueira (GIL, 2000), a pesquisa traz as seguinte questão problema: Os conteúdos da Educação Física quando abordados no AEE podem auxiliar o aluno com deficiência visual na aprendizagem do conteúdo referente à essa disciplina?

Quanto ao objetivo geral, este consistiu em verificar o efeito da prática de contraturno abordando os conteúdos da disciplina de Educação Física, aplicados em alunos com deficiência visual que frequentam o AEE do município de Marechal Cândido Rondon, levando os consideração a aprendizagem destes conteúdos.

\section{MÉTODOS}

\subsection{DESIGN DA PESQUISA}

Essa pesquisa caracterizou-se como de intervenção, ou "pesquisa-ação", que de acordo Gil (2008), é um tipo de pesquisa social concebida e realizada em associação com uma ação ou resolução de um problema coletivo. Ou seja, os pesquisadores e os participantes estiveram envolvidos de modo cooperativo ou participativo no estudo. $O$ qual neste caso os pesquisadores foram responsáveis pela elaboração e aplicação das aulas, após diálogo junto com os professores a respeito do conteúdo desenvolvido durante as aulas no ensino regular.

\subsection{SUJEITOS}

A seleção dos sujeitos foi realizada por meio da escolha por conveniência, ou seja, a amostra depende do julgamento do pesquisador (MARCONI e LAKATOS, 2005). Deste modo, os sujeitos da pesquisa foram:

1. três alunos com deficiência visual, dois do gênero feminino e um do gênero masculino, sendo todos os quais frequentam o AEE do município de Marechal Cândido Rondon-PR, matriculados nos Anos Finais do Ensino Fundamental;

2. dois professores de Educação Física dos respectivos alunos no ensino regular;

3. dois pesquisadores do gênero feminino, os quais têm experiência no ensino e pesquisa envolvendo atividade física e a pessoa com deficiência.

\subsection{INSTRUMENTOS}

Foram empregados dois instrumentos elaborados pelos pesquisadores, sendo que estes perfizeram-se em protocolos em forma de pré e pós testes e entrevistas 
pessoais seguindo um roteiro estruturado, da qual esta permite que os pesquisadores visam os interesses do estudo, bem como se aprofunde nas respostas dadas pelos participantes (PATTON, 2002).

\subsubsection{Pré e pós testes}

A cada aula ministrada foram preenchidos protocolos em forma de pré e pós testes que eram construídos após o planejamento de cada uma das aulas, já que estes variavam de acordo com o objetivo de cada aulas em questão. Todos os protocólos foram ajustados após aplicação do teste piloto, destinado para fazer possíveis modificações no instrumento e obter uma prévia análise dos resultados (THOMAS e NELSON, 2002). Assim, as mesmas realizadas no início da aula eram repetidas ao final dela, para que, através disso, fosse possível avaliar a progressão da aprendizagem dos alunos em relação ao conteúdo desenvolvido durante cada uma das aulas ministradas.

\subsubsection{Entrevistas pessoais}

Após um trimestre de aulas realizadas, como meio de analisar a percepção dos alunos com DV e dos professores de Educação Física do ensino regular a respeito da disciplina de Educação Física enfatizada no AEE, o segundo instrumento pautouse em entrevistas pessoais destinadas aos mesmos, do tipo face a face, que para Thomas, Nelson e Silverman (2012), esta é mais adaptável. As perguntas podem ser reformuladas e pode-se buscar esclarecimento por meio de questões subsequentes. Nela, o entrevistador pode observar como o entrevistando responde e, após, discernir melhor a intensidade dos sentimentos do entrevistado.

Estas foram realizadas pessoalmente com os professores na forma de gravação, com uso de gravador no formato de MP3, e o roteiro dos questionamentos foram realizados pelos pesquisadores. Estes visavam ter conhecimento de como abordariam a experiência com a respectiva prática no contraturno, bem como, suas opiniões quanto à relação entre o ensino regular e o AEE.

\subsection{PROCEDIMENTOS DE COLETA DE DADOS}

$1^{\circ}$ etapa: visita à SRM e as escolas do município de Marechal Cândido Rondon-PR visando apresentar e solicitar a autorização da realização da pesquisa;

$2^{\circ}$ etapa: aprovação dos professores e dos pais dos alunos para participar da pesquisa através do Termo de Consentimento Livre Esclarecido;

$3^{\circ}$ etapa: aprovação do Comitê de Ética em pesquisa, com o parecer número 2.442.027, CAAE número 80388117.4.0000.0107, do dia 15 de novembro de 2017;

$4^{\circ}$ etapa: visita às escolas com o objetivo de verificar com os professores de Educação Física quais conteúdos estariam trabalhando com a turma dos respectivos alunos no ensino regular, os quais foram os mesmos que os pesquisadores trabalharam na intervenção, no contraturno; 
$5^{\circ}$ etapa: planejamento e realização das aulas do contraturno, sendo que estas foram elaboradas e aplicadas pelos pesquisadores, dentro de um trimestre, realizadas uma vez por semana, compreendendo o tempo de 50 minutos cada. Porém, por haver algumas semanas sem aula, ao total foram realizadas 10 aulas aos alunos 1 e 2 e ao aluno 3, que faltou cinco dias, só foram realizadas cinco aulas, e estas ocorreram de forma individualizada já que o conteúdo abordado à ele era outro. Já o 1 e 2 fizeram as aulas em um mesmo momento, pois ambos também frequentavam a mesma turma no ensino regular, o que significa que professor estaria trabalhando o mesmo conteúdo com eles.

$6^{\circ}$ etapa: aplicação da entrevista aos alunos e professores.

\subsection{ANÁLISE DOS DADOS}

A análise dos dados foi pautada de modo qualitativo, que conforme Thomas, Nelson e Silverman. (2012), o investigador é o instrumento da coleta e da análise dos dados. Este deve exibir sensibilidade e boa percepção ao coletar e analisar os dados, dos quais estes também costumam ser apresentados por palavras, descrições e imagens.

\section{RESULTADOS}

Para melhor compreensão dos dados coletados, os resultados foram organizados em três subcapítulos, sendo eles: pré e pós testes; entrevistas aos alunos acerca de suas percepções quanto às intervenções; entrevista aos professores acerca de suas percepções quanto ao AEE.

\subsection{PRÉ E PÓS TESTES RELACIONADOS ÀS INTERVENÇÕES PRÁTICAS}

Os conteúdos trabalhados foram Esporte, Jogos e Brincadeiras e Práticas Corporais de Aventura, sendo que cada aula foi planejada e descrita em forma de planos de aula anteriormente ao seu desenvolvimento prático.

Os testes eram realizados a cada aula ministrada e continha questões relacionadas ao objetivo da aula em questão e era exercido no início e no final da aula, como forma de verificar se houve progressão do aprendizado pré e pós cada aula.

Tendo em consideração os conteúdos trabalhados, toda aula após os pré testes era realizado uma conversa inicial como forma de abordar teoricamente respectivo conteúdo e em seguida vivenciavam a prática. Nos casos das modalidades esportivas, foram construídas maquetes táteis para que os alunos tocassem e conhecessem as demarcações da quadra da modalidade em questão. Após a conversa inicial era realizado a prática com os alunos enfatizando as questões tratadas na teoria. Nos casos em que era a primeira aula trabalhando uma respectiva modalidade, os alunos iniciavam a parte prática conhecendo os materiais que englobam tal através do toque 
e manuseio. Seguidamente, usando o pesquisador como guia, andavam pela quadra para ter uma noção espacial da sua extensão, e após conheciam e vivenciavam os aspectos técnicos da respectiva modalidade.

Em geral, era enfatizado atividades que variavam de acordo com o objetivo de cada aula, sempre visando que o aluno não essencialmente se tornasse um especialista em determinados movimentos exigidos na modalidade, mas que conhecesse cada um deles, identificasse sua importância, soubesse diferenciá-los e tentassem executá-los, isso sempre tendo em vista que a ausência (ou quase ausência) da visão não o impedisse de tal tarefa.

Como exemplos de atividades, quando trabalhado o Parkour, conteúdo específico das Práticas Corporais de Aventura, foram distribuídos vários obstáculos diferentes que exigissem a execução dos movimentos presentes na modalidade, como a corrida, aterrissagem, equilíbrio, passar por baixo, saltar/pulos, rolamento e virada. Após esta etapa da aula os alunos eram direcionados para um feedback final e retomado o teste inicial.

Deste modo, as tabelas abaixo refletem como se deu os resultados desta etapa, sendo que a tabela 1 se refere aos alunos 1 e 2 e a tabela 2 ao aluno 3 , já que as aulas eram diferenciadas:

Quadro 1 - Pré e pós testes do aluno 1 e 2

\begin{tabular}{|c|c|c|c|c|c|}
\hline \multirow{2}{*}{ Aulas } & \multirow{2}{*}{$\begin{array}{c}\text { Número de } \\
\text { questões } \\
\text { realizadas nos } \\
\text { testes }\end{array}$} & $\begin{array}{c}\text { Acertos nos } \\
\text { pré testes }\end{array}$ & $\begin{array}{c}\text { Acertos nos } \\
\text { pós testes }\end{array}$ & $\begin{array}{c}\text { Acertos nos } \\
\text { pré testes }\end{array}$ & $\begin{array}{c}\text { Acertos nos } \\
\text { pós testes }\end{array}$ \\
\cline { 5 - 6 } & 9 & 5 & & 2 & 9 \\
\hline 1 & 4 & 4 & 4 & 0 & 4 \\
\hline 2 & 4 & 0 & 3 & 0 & 4 \\
\hline 3 & 4 & 2 & 4 & 1 & 4 \\
\hline 4 & 5 & 1 & 4 & Ausente & Ausente \\
\hline 5 & 5 & Ausente & Ausente & 4 & 5 \\
\hline 6 & 2 & 0 & 2 & Ausente & Ausente \\
\hline 7 & 7 & Ausente & Ausente & 1 & 6 \\
\hline 8 & 4 & 1 & 1 & 1 & 4 \\
\hline 9 & 5 & Ausente & Ausente & 0 & 4 \\
\hline 10 & & & & & \\
\hline
\end{tabular}

Fonte: dados dos pesquisadores

Quadro 2 - Pré e pós testes do aluno 3

\begin{tabular}{|c|c|c|c|}
\hline Aula & Número de questões & $\begin{array}{c}\text { Acertos nos pré } \\
\text { testes }\end{array}$ & $\begin{array}{c}\text { Acertos nos pós } \\
\text { testes }\end{array}$ \\
\hline 1 & 8 & 3 & 5 \\
\hline 2 & 4 & 0 & 3 \\
\hline 3 & 4 & 0 & 3 \\
\hline 4 & 7 & 1 & 5 \\
\hline 5 & 5 & 1 & 2 \\
\hline
\end{tabular}

Fonte: dados dos pesquisadores 
Por meio dos quadros expostos pode-se perceber que, com exceção da segunda aula em que o aluno 1 respondeu todas as perguntas corretamente já nos pré testes, pode-se perceber que todas as demais aulas, os três alunos sempre mostraram avanços nos pós testes, comparando-se com seus pré testes. Para ilustrar essa informação, o gráfico a seguir aborda a análise geral da progressão de aprendizado dos alunos. Para isso, foram somadas os números de todas as questões realizadas aos alunos, número de acertos nos pré testes e número de acertos nos pós testes, isso conforme as presenças dos alunos nas aulas.

Gráfico 1 - Progressão do aprendizado dos alunos nas intervenções

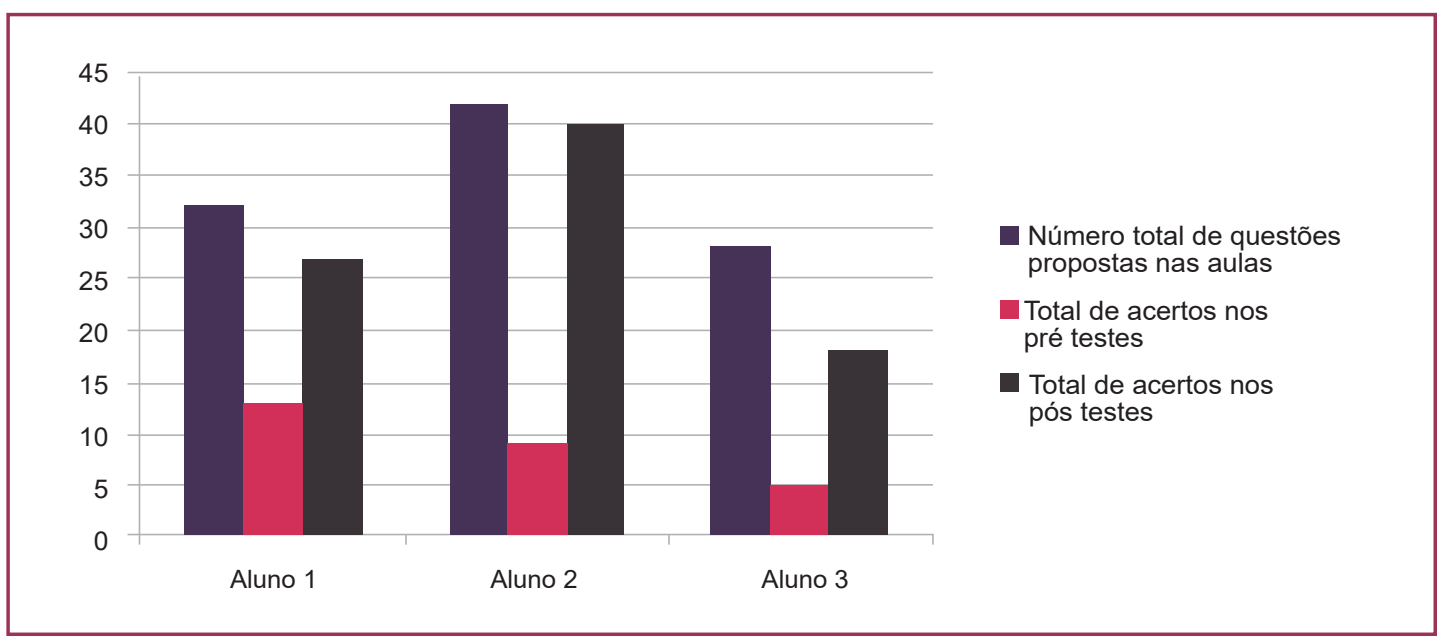

Fonte: dados dos pesquisadores

Visualizando o gráfico, pode-se concluir que o número de questões propostas e o número de acertos nos pós testes tiveram similaridades, mostrando que os acertos nos pós testes foram maiores que nos pré testes. Ou seja, progrediu-se no aprendizado. Isso é bem enfatizado ao aluno 2, por exemplo, que de 42 questões propostas ao total, nos pré testes ele acertou 9 e no pós testes progrediu para 40.

\subsection{ENTREVISTAS COM OS ALUNOS}

Para verificar como se deu a etapa acerca das percepções dos alunos quanto às aulas no contraturno e suas percepções em relação à finalidade do $A E E$, após o término das intervenções foram realizadas entrevistas aos mesmos, que visavam abordar cinco questionamentos:

Em relação a primeira questão: "A disciplina de Educação Física já foi, de alguma forma, enfatizada no AEE", todos os alunos relataram que a presente intervenção foi a primeira oportunidade que tiveram em vivenciar os conteúdos da Educação Física no contraturno, através do AEE.

Por meio disso, é possível verificar um distanciamento entre a teoria e a prática, quando mesmo descrito como direito a complementação e/ou suplementação das disciplinas do ensino regular noAEE (BRASIL, 2008), na prática nem todas as disciplinas são abordadas, neste caso, a Educação Física. Ou seja, o aprendizado da Educação Física torna-se prejudicado no processo de aprendizado dos alunos com DV. 
Quanto à segunda pergunta: "se aulas propostas atingiram as expectativas acerca da didática desenvolvida", todos os alunos relataram que a forma em que foram abordados os conteúdos ficou compreensível e adequado. Desta forma, insinuando que não visualizaram nenhum impasse no desenvolvimento das aulas.

No que concerne à terceira pergunta: "se notaram que a intervenção fortaleceu a assimilação do conteúdo da disciplina de Educação Física desenvolvido durante as aulas no ensino regular", o aluno 1 foi o único que abordou uma relação entre as aulas do ensino regular e a nossa intervenção no contraturno, afirmando que:

As aulas foram muito úteis, pois aprendi coisas novas. Teve algumas coisas que eram realizadas nas aulas de Educação Física no ensino regular e estas eram transmitidas de forma adaptada para nós aqui no contraturno, facilitando nosso aprendizado.

Já o aluno 2, relatou que:

Eu nem sempre participo nas aulas do ensino regular, só participo quando a professora faz algo que eu posso participar, por exemplo, o Goalball. No mais, acho que não teve nenhuma relação, pois eu sempre fico de fora e não sei o que eles fazem na aula.

Através disso, ao analizar as falas dos alunos, se visualiza um distanciamento entre a fala do aluno 1 e 2, mesmo ambos frequentando a mesma turma no ensino regular. Isso possivelmente se dá pelo fato que o aluno 1 , com seus $20 \%$ de visão, ainda consegue participar junto com os demais colegas da turma sem que o professor necessite realizar adaptações na aula, já o aluno 2 não consegue compreender facilmente essas informações comparado com os demais alunos, pois sendo cego, necessita de maiores adaptações na aula por conta de sua limitação, e se esta não é realizada, o aluno acaba tendo dificuldade de participar ou, no caso do respectivo aluno, incapaz.

Em relação ao aluno 3, este não citou exemplo de relações entre o ensino regular e a intervenção, mas fez a seguinte afirmação:

Sim, eu conversei com o professor do ensino regular sobre o que eu aprendi com vocês, as principais informações que foram passadas em relação aos esportes trabalhados nas nossas aulas e isso foi ótimo, ele achou interessante.

Relacionado à quarta questão: "se pensam que as práticas do AEE podem auxiliar no aprimoramento dos conteúdos referente à disciplina de Educação Física", todos responderam que sim, priorizando as seguintes justificativas:

Aluno 1: Sim, pois é transmitido coisas novas para nós, por exemplo, os tipos de passes no Futsal, antes das nossas eu não tinha noção das diferentes formas de fazê-lo, agora sim. [...]. Também, porque temos mais tempo de experimentar determinada prática, o que amplia nosso aprendizado.

Aluno 2: Sim, se tiver uma ligação entre os conteúdos desenvolvidos nos dois.

Aluno 3: Provavelmente sim, pois eu comentei com a [...] (professora responsável pela SRM) o que a gente fazia nas aulas e ela gostou bastante.

Estes comentários atestam a importância das práticas do AEE, mostrando a aprovação dos alunos com determinadas ações que são, na maioria das vezes, promovidas nos ambientes das SRMs.

Finalizando, foi questionado aos alunos se "gostariam de se envolver novamente com práticas do AEE voltadas à disciplina de Educação Física” todos assentiram, manifestando-se positivamente: 
Aluno 1: Sim, para continuar aprendendo coisas novas e ampliar o aprendizado da disciplina de Educação Física.

Aluno 2: Sim.

Aluno 3: Sim, gostaria, pois achei legal e importante.

\subsection{ENTREVISTAS AOS PROFESSORES}

Para verificar como se concerniu a etapa acerca das percepções dos professores quanto ao AEE, após o término das intervenções foram realizadas entrevistas aos mesmos:

As entrevistas visavam abordar quatro questionamentos, sendo eles: 1. Já tiveram alunos com DV anteriormente; 2 . Sentem dificuldades em incluí-los nas aulas e como são suas participações; 3. Conhecem o AEE e sua finalidade; 4. Quais suas opiniões a respeito dos conteúdos da Educação Física enfatizados nos AEEs.

Quanto ao primeiro questionamento, "se os professores já tiveram alunos com DV anteriormente" ambos relataram que não, que esta foi a primeira vez que tiveram alunos com determinada característica em suas turmas, inclusive o professor 2 que possui 23 anos de profissão. Assim, pode- se constatar que ambos os professores apresentam pouca experiência com suas práticas pedagógicas relativas à alunos com DV.

Sobre se "apresentam dificuldades em incluir os alunos com DV nas aulas e como são suas participações", os entrevistados manifestaram as seguintes opiniões:

Professor 1: Sinto, mas nem por isso deixo de incluí-los. Tento adaptar e/ou promover atividades que atenda suas limitações.

Professor 2: Sim, sinto... Eu percebo que a aluna não teve uma boa educação básica, provavelmente por descomprometimento da família, ela tá no $8^{\circ}$ ano, mas é nítido que foi falha a educação dela no passado. Quando eu interajo com ela, e explico o conteúdo especialmente à ela, ela assimila tudo com muita facilidade. Nas avaliações eu faço oralmente com ela [...] Nas aulas práticas tento explorar o máximo, a deixo apalpar os materiais que utilizamos durante as aulas e tudo mais. O que atrapalha mesmo seu aprendizado é a dificuldade de envolvimento da turma com ela, que esta nem sempre colabora [...].

Ao realizar uma entre o professor 1 e o aluno 2, se percebe uma contradição entre suas falas. Enquanto o professor diz tentar adaptar a aula para que seus alunos com DV possam estar sempre incluídos nesta, o aluno 2 discorda afirmando que nem sempre se faz ativo na aula, já que a forma com que ela é desenvolvida nem sempre o permite.

O professor 2 relata que o aluno não teve uma boa educação básica e, mesmo não deixando bem claro, tenta evidenciar que este seja um dos motivos que dificultam ainda mais o trabalho com ele. Após afirma que o aluno tem facilidade na compreensão do conteúdo quando o professor aborda-o em particular com ele, entretanto ele acaba não sendo claro quanto às participações do aluno nas aulas práticas.

Considerando que os professores devam mostrar conhecimento do AEE, já que o mesmo adentra-se nos projetos pedagógicos das escolas (BRASIL, 2008). No que se concerne a questão se "conhecem o AEE e sua finalidade?", os docentes expõem o desconhecimento, relatando que: 
Professor 1: Já ouvi falar, tenho noção que os alunos frequentam, mas não sei como funciona, quais seus objetivos.

Professor 2: Não, eu não tenho nenhum conhecimento. Já soube da professora responsável pelo AEE visitar a escola aqui e expor seu trabalho, mas eu nunca tive nenhum contato com ela.

Essas elucidações confirmam a informação trazida na entrevista com os alunos, quando todos revelaram que a disciplina de Educação Física nunca havia sido abordada no AEE. Assim, se constata a ausência de um diálogo entre o professor de Educação Física do ensino regular e o professor do ensino especial, que atua na SRM, mostrando que o distanciamento entre a teoria e a prática permanece presente na educação formal.

Levando em consideração a envoltura que os professores tiveram com a prática do contraturno, através das intervenções, os docentes manifestaram as seguintes opiniões a respeito da enfatização dos conteúdos da Educação Física nos AEEs :

Professor 1: Eu acho que a disciplina deveria ser privilegiada no AEE, pois como as outras disciplinas, a Educação Física também é um direito do aluno.

Professor 2: Acho muito importante a ideia do AEE abordar os conteúdos da disciplina de Educação Física. Lógico, isso dependeria de nós como professores se unirmos para realizar um bom trabalho [...]. A ideia que vocês propuseram foi muito boa, a aluna sempre me relatou o que vocês faziam com ela e as coisas novas que havia aprendido. Então, acredito que sim, seria uma forma de aprimorar seus aprendizados na disciplina.

Através das afirmações, percebe-se que eles compreendem a importância do AEE e de suas funções enquanto mediadores no processo de aprendizado dos conteúdos da disciplina de Educação Física aos alunos com DV que frequentam o mesmo.

\section{DISCUSSÃO}

O presente estudo aponta para a necessidade de se promover um trabalho entre o ensino regular e o AEE, para que juntos se possa construir um caminho que privilegie o aprendizado do educando com DV. É possível verificar que as práticas nos AEEs, quando envolvem a disciplina de Educação Física, promovem maiores alternativas de adaptações aos alunos com DV, já que o professor acaba tendo um tempo reduzido para esses alunos, e com isso, sua atenção se volta exclusivamente às limitações destes.

A presente pesquisa tem similaridade com o estudo de Alves e Duarte (2005) quando evidenciam que todo aluno com baixa visão ou cegueira tem possibilidade de participar da realização dos mesmos conteúdos que os demais, cabendo apenas ao professor adaptar sua aula para que esta também alcance esses alunos. Assim, confirmase que o AEE amplia as opções de trabalho junto do aluno com DV e derruba as barreiras que limita o professor nas turmas do ensino regular (ALVES; DUARTE, 2005).

Esta ideia é consentida por Soares e Baptista (2015) e Almeida (2015) ao elucidarem que o trabalho em parceria entre o professor de Educação Física e o 
professor de Educação Especial é possível no ensino regular, pois ambos contribuem com diferentes funções, e quando juntos, abarcam as lacunas no ensino da Educação Física ao aluno com deficiência. Ainda, a Educação Física apresenta a vantagem do aprendizado estar envolvido com a corporeidade e com momentos de socialização, assim os alunos participam com interesse e motivação.

Quanto às vivências dos professores de Educação Física a respeito do AEE, no estudo de Santos, Silva e Fumes (2014) foram entrevistados quatro professores de Educação Física e contatou-se que apenas um deles desconhecia o mesmo. Os demais conheciam, mas o descreviam de maneiras diferentes, não tendo muita objetividade em suas insinuações, comprovando o desconhecimento sobre a real função do AEE. Ainda, vale considerar que apenas um desses professores relatou que a disciplina de Educação Física é abordada nas SRMs. Assim, percebe-se uma similitude com o presente estudo, quando verificada a pouca ou quase ausência de envoltura com a disciplina de Educação Física no AEE, já que os professores participantes relatam o desconhecimento das ações do mesmo.

Em relação a essa questão, observou-se que a formatação das disciplinas nas escolas revelaram uma relação de poder e uma hierarquização dos conteúdos. Destarte, não é difícil entendermos a razão da Educação Física se tornar tão desvalorizada na escola, e consequentemente, desvinculada do AEE, já que na maior parte das vezes, ela aparece como uma atividade puramente recreativa (SOARES e BAPTISTA, 2015).

Deste modo, verifica-se a contradição com a fala de Rodrigues (2003, p. 69) quando salienta que "[...] a Educação Física (EF) como disciplina curricular não pode ficar indiferente ou neutra face a este movimento de Educação Inclusiva." Para isso, sugere-se uma preocupação maior com a formação inicial e continuada de professores de Educação Física na escola, discutindo e analisando como tratar os valores e atitudes nas aulas como possibilidade concreta de intervenção pedagógica, de modo que esta retrate sua importância no ambiente escolar (RODRIGUES; DARIDO, 2008).

Na pesquisa de Silva e Kato (2010) os mesmos concordam que as dificuldades em trabalhar com estes alunos residem no despreparo na formação inicial e/ou ausência da formação continuada dos professores. Seus resultados apontam para o desconhecimento das especificidades das patologias dos alunos e os métodos de ensino adequados à serem empregadas, o que faz com que a prática pedagógica do professor e a aprendizagem do aluno sejam comprometidas.

A presente pesquisa também evidenciou que os professores participantes sentem-se inseguros a receberem os alunos com DV isso pois nunca haviam sido confrontados com experiências de práticas em turmas nas quais haviam alunos com determinada característica. Casarotto e Krug (2016) também constataram essa realidade. Estes acreditam que a formação inicial dos professores entrevistados não ofereceu subsídios para a atuação em escolas de Educação Especial, ou seja, para que estes possuam domínio com o público alvo da Educação Especial.

Neste ínterim, concorda-se com Silva, Santos e Fumes (2014) quando denotam a necessidade de diálogo e troca de saberes constantes entre o professor 
de Educação Física e o professor do AEE, para que assim, juntos, contribuam para a efetivação de uma educação que crie soluções e estratégias constantes para o processo de ensino e aprendizagem do aluno com DV.

Isso posto, tendo consciência da presença do direito do aluno com deficiência perante lei (BRASIL, 1988; 2008) e das dificuldades demonstradas pelos professores de Educação Física em incluir o aluno com DV nas aulas, é incontestável alegar a necessidade dos professores do ensino regular e do AEE usufruírem desse decreto, criando maior envolvimento e diálogo entre eles, prezando o aprendizado desses alunos.

\section{CONSIDERAÇÕES FINAIS}

Tendo em vista que o objetivo da pesquisa foi verificar o efeito da prática de contraturno abordando os conteúdos da disciplina de Educação Física, aplicados em alunos com DV que frequentam o AEE do município de Marechal Cândido Rondon, a presente proposta mostrou efeitos positivos quanto às aulas de Educação Física realizadas no contraturno, através do AEE. Ou seja, por meio das aulas realizadas houve a aprendizagem dos conteúdos propostos.

Foi possível perceber que a função do AEE ainda é desconhecida pelos professores de Educação Física investigados, e consequentemente, que os conhecimentos da referida disciplina não são elencados nele. Deste modo, constatouse o não cumprimento do direito previsto no documento da Política Nacional de Educação Especial que complementa/suplementa os conhecimentos do ensino regular através do AEE (BRASIL, 2008). Ainda, evidenciou-se por meio de relatos dos alunos com DV, que os mesmos não participam de todas as aulas de Educação Física no ensino regular, ou seja, tem-se negado seu direito ao aprendizado da referida disciplina.

Destarte, com a convicção de cumprir com o exposto da Política Nacional de Educação Especial, a pesquisa confirma que é possível, quando em diálogo entre o professor de Educação Física do ensino regular e o professor do ensino especial, incrementar e fortalecer os conhecimentos da Educação Física no AEE aos alunos com DV, mostrando efeitos positivos ao direito previsto no documento supracitado. Aqui vale destacar que mesmo que a prática no contraturno, neste caso, tenha sido realizada pelos pesquisadores que têm formação em Educação Física, não impede de que o professor de Educação Física do ensino regular seja responsável por mediar o professor do AEE (o qual não tem uma formação específica na área) através do diálogo, de forma que o professor do AEE seja responsável apenas por colocar na prática suas colocações.

Desta forma, isso pode auxiliar o professor de Educação Física em incrementar e fortalecer o aprendizado ao aluno com DV, o que foi comprovado nos testes realizados, bem como nos relatos dos professores e alunos envolvidos sobre os benefícios da proposta. Isso posto, é possível concluir que as práticas no contraturno, através do AEE, ampliam o leque das possibilidades de adaptações nas atividades realizadas, mostrando que além do ensino regular, é importante o 
fortalecimento do conteúdo no AEE, para que possam haver uma maior participação nas atividades ao público com deficiência já que deste modo as limitações destes são mais valorizadas e respeitadas, pois há uma atenção única para eles neste ambiente, e, consequentemente, estes alunos têm maior facilidade em absorver o conteúdo enfatizado.

Recomenda-se estudos que possam investigar a formação inicial e continuada de professores de Educação Física envolvendo as temáticas da Educação Especial, bem como, pesquisas que tratam do Ensino Colaborativo nas aulas de Educação Física. Sugere-se ainda o desenvolvimento de mais pesquisas de intervenções junto de alunos com deficiência no ensino regular, para que os professores de Educação Física tenham maiores subsídios, não apenas em como incluir este aluno, mas também, como fazer com que o mesmo nutre, de fato, o aprendizado.

\section{REFERÊNCIAS}

ALMEIDA, Luiz Fernando Garcia. Inclusão nas aulas de Educação Física: Relato de experiência entre turmas da educação especias e turmas regulares. In: CONGRESSO NACIONAL DE EDUCAÇÃO (EDUCERE), 12., 2015, Curitiba. [Anais...]. Curitiba: PUCPR, 2015.

ALVES, Maria Luiza. Tanure; DUARTE, Edison. A inclusão do deficiente visual nas aulas de Educação Física Escolar: impedimentos e oportunidades. Acta Scientiarum. Human Social. Sciences, v. 27, n. 2, p. 231-237, 2005.

BRASIL. Constituição da República Federativa do Brasil de 1988. Brasília: Senado Federal, 1988.

BRASIL. Diretrizes Nacionais para a Educação Especial na Educação Básica. Brasília: MEC/SEESP, 2001a.

BRASIL. Lei n. 9.394/1996. Lei de Diretrizes e Bases da Educação Nacional. Diário Oficial da União, Brasília, DF, seção 1, n. 248, p. 2783923, 23 dez. 1996.

BRASIL. Lei $n^{\circ}$ 13.146, de 9 de jul. de 2015. Estatuto da pessoa com deficiência. Brasília, 2015.

BRASIL. Parâmetros Curriculares Nacionais: Educação Física. 3. ed. Brasília: MEC/SEF, 2001b.

BRASIL. Política de Educação Especial na perspectiva da Educação Inclusiva. Brasilia: Ministério da Educação, 2008.

CASAROTTO, Verônica Jocasta; KRUG, Hugo Norberto. O processo de construção dos saberes docentes de professores de Educação Física atuantes em escolas de Educação Especial. Revista Holos, v. 8, n.1, p. 338-378, 2016.

CONCEIÇÃO, Vitor Julierme Santos; VASSOLER, Bruna Coelho; FRASSON, Jéssica Serafim. A prática pedagógica de professores de educação física frente à inclusão escolar. Revista Kinesis, v.2, n. 32, p. 36-51, 2014. 
CUNHA, Raíssa Forte Pires; GOMES, Adriana Leite Limaverde. Concepções de professores de Educação Física sobre inclusão escolar. Práxis Educativa, v. 12, n. 2, p. 414-429, 2017.

GIL, Antonio Carlos. Métodos e técnicas de pesquisa social. 6.ed. São Paulo: Atlas, 2008.

GIL, Marta. Deficiência Visual. Brasília: Ministério da Educação: Secretaria de Educação a Distância, 2000.

KAFROUNI, Roberta Mastrantonio; PAN, Miriam Aparecida Graciano de Souza. A inclusão de alunos com necessidades educativas especiais e os impasses frente à capacitação dos profissionais da educação básica: um estudo de caso. InterAÇÃo, p.1-8, 2001.

LARA, Fabiane Matos; PINTO, Celeida Belchior Garcia Cintra. A importância da educação física como forma inclusiva numa perspectiva docente. Revista Brasileira de Ciências da Saúde, v. 15, n. 1, p. 67-74, 2017.

MARCONI, Marina de Andrade; LAKATOS, Eva Maria. Fundamentos de metodologia científica. 6.ed. São Paulo: Atlas, 2005.

MUNSTER, Mey de Abreu Van; ALVES, Maria Luíza Tanure. Educação Física e Inclusão de Estudantes com Deficiências no Brasil: Contrapontos entre legislação e produção científica.

Revista da Sobama, v.19, n.2, p. 171-184, 2018.

PARANÁ. Diretrizes Curriculares da Educação Básica. Educação Física. Curitiba: Secretaria de Estado da Educação do Paraná: Departamento de Educação Básica, 2008.

PATTON, Michael Quinn. Qualitative Research and Evaluative Methods. Califórnia: Sage, 2002.

RODRIGUES, David. A educação física perante a educação inclusiva: reflexões conceptuais e metodológicas. Revista da Educação Física/ UEM, v.14, p. 67-73, 2003.

RODRIGUES, Heitor de Andrade; DARIDO, Suraya. Cristina. As três dimensões dos conteúdos na prática pedagógica de uma professora de Educação Física com mestrado: um estudo de caso. Revista da Educação Física/UEM, v. 19, n. 1, p. 51- 64, 2008.

ROPOLI, Edilene Aparecida; MANTOAN. Maria Tereza Eglér.; SANTOS, Maria Terezinha da Consolação Teixeira; MACHADO. Rosângela. A Educação Especial na perspectiva da inclusão escolar: A escola comum inclusiva. Brasília: Ministério da Educação, Secretaria de Educação Especial, 2010.

SILVA, Francy Kelle Rodrigues.; SANTOS, Darllanea Nascimento; FUMES, Neiza de Lourdes Frederico. Os professores de Educação Física Escolar e o Atendimento Educacional Especializado nas escolas públicas. Revista da Sobama, v. 15, n. 2, p. 31-36, 2014.

SILVA, Ricardo Souza; KATO, Ademilde Aparecida Gabriel. Adaptações curriculares para o ensino- aprendizagem de alunos com baixa visão. Revista Eventos pedagógicos. v. 1, n. 1, p.66-74, 2010.

SOARES, Carlos Henrique Ramos.; BAPTISTA, Claudio Roberto. Atendimento Educacional Especializado e Educação Física: Possibilidades cooperativas no cotidiano escolar. Revista Cocar, n.1, p. 57-79, 2015.

THOMAS, Jerry R.; NELSON, Jack. K. Métodos de pesquisa em atividade física. 3. ed., Porto Alegre: Artmed, 2002. 
THOMAS, Jerry R.; NELSON, Jack K.; SILVERMAN, Stephen J. Métodos de pesquisa em atividade física. Porto Alegre. Artmed, 2012.

UNESCO. Declaração de Salamanca. Sobre princípios, políticas e práticas da área das necessidades educativas especiais. Salamanca-Espanha,1994.

\section{Apoio:}

Universidade Estadual do Oeste do Paraná (UNIOESTE) 